\title{
PAPEIS QUE GUARDAM MEMÓRIAS DE UMA PROFESSORA POLIVALENTE: MIRADAS PARA AS AULAS DE HISTÓRIA (COLÉGIO DE APLICAÇÃO/UFRGS - 1978- 1986)
}

\author{
PAPELES QUE GUARDAN MEMORIAS DE UN PROFESOR MULTIPROPÓSITO: VISTAS PARA CLASES DE \\ HISTORIA (COLÉGIO DE APLICAÇÃO/UFRGS-1978-1986) \\ PAPERS THAT KEEP MEMORIES OF A MULTIPURPOSE TEACHER: SIGHTS FOR HISTORY CLASSES \\ (COLÉGIO DE APLICAÇÃO/UFRGS - 1978-1986)
}

ALMEIDA, Doris Bittencourt ${ }^{1}$

\begin{abstract}
RESUMO
O artigo investiga seis cadernos de planejamento de uma professora polivalente do Colégio de Aplicação (UFRGS), em que descreve suas aulas, entre 1978 e 1986. Entendem-se esses artefatos como testemunhos da cultura escolar, na perspectiva da singularidade das escritas ordinárias. Metodologicamente, analisaram-se as práticas desenvolvidas nas aulas de História, em suas dimensões, recorrências, relações com outros componentes curriculares e transformações ao longo dos anos. Cadernos como esses comumente são vistos como resíduos da escola, entretanto, conservam sua potência como documentos inscritos nos campos da História da Educação em suas interfaces com a História da Cultura Escrita.
\end{abstract}

Palavras-chave: Cadernos escolares. Ensino polivalente. Colégio de Aplicação. Arquivos pessoais. Cultura escolar.

\section{ABSTRACT}

The articleinvestigatessix notebooks ofplanning a general-purposeApplication high schoolteacher (UFRGS), in whichhedescribeshis classes, between 1978 and 1986. Meanstheseartifacts as testimoniesofschoolculture, in viewoftheuniquenessofthewritings. Methodologically, analyzedthepracticesdeveloped in history, in its dimensions, recurrences, relationswithother curricular componentsandtransformations over theyears. Notebooks like thesecommonly are seen as wasteofschool, however, retainyourpower as documentsentered in thefieldsofhistoryofeducation in its interfaces withthehistoryofWrittenCulture.

Keywords: School notebooks. All-round education. Schoolofapplication. Personal files. Schoolculture.

\section{RESUMEN}

El artículo investiga seis cuadernos de planificación de unprofesor de escuela secundaria (UFRGS), de aplicación general enel que describe sus clases, entre 1978 y 1986. Significa que estosartefactos como testimonios de la cultura escolar, teniendoencuentalasingularidad de las escrituras. Metodológicamente, se analizaronlasprácticasdesarrolladasenlahistoria, en sus dimensiones, lasrepeticiones, las relaciones conotros componentes curriculares y transformaciones durante losaños. Cuadernos como estoscomúnmenteson vistos como basura de laescuela, sin embargo, conservar su poder como documentos ingresarenlos campos de lahistoria de laeducaciónen sus interfaces conlahistoria de la cultura escrita.

Palabras clave: Cuadernos escolares. Educación integral. Escuela de aplicación. Archivospersonales. Cultura de laescuela.

\footnotetext{
1 Universidade Federal do Rio Grande do Sul - UFRGS - Porto Alegre - Brasil
} 


\section{INTRODUÇÃO}

Neste texto, investigam-se cadernos de planejamento de uma professora do Colégio de Aplicação (CAp/UFRGS), que os conservou por muitos anos. Foram selecionados seis cadernos em que Isabel Loss, professora polivalente, descreve suas aulas para a sexta série do primeiro grau de ensino, entre os anos 1978 e 19862. Objetiva-se problematizar esses escritos, testemunhos da cultura escolar ${ }^{3}$, na perspectiva da singularidade das escritas ordinárias. Metodologicamente, o foco do estudo consiste no exame dos artefatos, sobretudo no que se refere às práticas das aulas de História, como componente curricular, em suas recorrências, interfaces com outros campos disciplinares e transformações ao longo dos anos. Tais práticas se inscrevem em um modelo de escola considerado de vanguarda pedagógica, a partir de sua idealização por Graciema Pacheco e Isolda Paes4.

Sobre o colégio, cabe dizer que foi fundado em 1954, pela Faculdade de Filosofia, vinculada ao Departamento de Educação. Entre seus objetivos, buscava promover a prática docente de estagiários dos Cursos de Licenciatura da Universidade, bem como, legitimar-se como campo de investigação pedagógica (SCHUTZ, , 1994). Em 1971, logo após a Reforma Universitária5 ${ }^{5}$ a Faculdade de Filosofia teve seus cursos desmembrados, fato que promoveu a constituição da Faculdade de Educação como unidade acadêmica. Até 1996, a Faculdade de Educação e o Colégio de Aplicação dividiram o mesmo prédio no Campus Central da UFRGS, que havia sido construído para outros fins ${ }^{6}$. Em termos pedagógicos, o CAp emerge como instituição com forte difusão dos discursos de renovação educacional, que tiveram um papel importante na constituição de um determinado ethos de escola diferenciada em Porto Alegre ${ }^{7}$.

Com relação à formação de Isabel Loss, sabe-se que cursou a Escola Normal no Colégio Sevigné, ${ }^{8}$ em Porto Alegre. Em seguida, graduou-se em Ciências Sociais na PUCRS ${ }^{9}$. Em 1978, começou a lecionar no Colégio de Aplicação, como professora polivalente ${ }^{10}$ da quinta e sexta série do primeiro grau

${ }^{2}$ Foram examinados os cadernos dos seguintes anos: 1978, 1979, 1982, 1984, 1985, 1986.

3 VinãoFrago explica que a escola possui uma cultura escolar, mas precisamente culturas escolares, ou seja, um conjunto de aspectos institucionalizados que caracterizam a escola, em diferentes níveis, considerando as questões sociológicas, antropológicas, históricas, e as práticas cotidianas que constituem essa instituição. Por esse conjunto de aspectos institucionalizados, o autor entende "as práticas e condutas, modos de vida, hábitos e ritos, a história cotidiana do fazer escolar, objetos materiais, funções, usos, espaço, materialidade física, simbologia, (...). Alguém dirá: tudo. E é certo, a cultura escolar é toda a vida escolar: feitos e ideias, mentes e corpos, objetos e condutas, modos de pensar, dizer e fazer" (1995, p. 68-69).

${ }^{4}$ O Colégio teve a presença constante de Graciema Pacheco, por vinte e sete anos à frente da instituição (1954-1981). Ao lado dela, estava Isolda Holmer Paes, como Vice-Diretora, por cerca de vinte anos (Lima, 2016).

${ }^{5}$ Reforma Universitária de 1968, Lei 5.540 (28/11/1968).

${ }^{6}$ A proposta original do prédio era sediar o Instituto Nacional de Estudos Pedagógicos (INEP) no RS.

7 Para maiores informações consultar Lima e Almeida, 2018.

8 O Colégio Sevigné foi fundado em 1900 em Porto Alegre por Emmeline Courteilh esposa do cônsul da França, instituição voltada à formação docente para mulheres. Para maiores informações, consultar Werle, 2008.

9 Informações concedidas pela professora

${ }^{10} \mathrm{~A}$ designação, sexto ano polivalente (que nos anos 1970 designou-se sexta série polivalente), os motivos para sua instalação e o público a que se destinava relacionam-se à Lei de Diretrizes e Bases da Educação de 1961 ao determinar que o Ensino Primário tivesse no mínimo, quatro séries elementares que poderiam ser estendidas por mais duas, complementares. Estas últimas séries, quinta e sexta, deveriam ser ministradas àqueles que não iniciassem o Ensino Ginasial após o término do quarto ano primário e 
de ensino, instituição em que permaneceu até 2012, quando se aposentou. Para melhor entender o conceito da polivalência na docência, é preciso lembrar que os fundamentos do CAp buscaram aproximações das Classes Nouvelles ${ }^{11}$ francesas, que defendiam a manutenção de poucos docentes atuando no trabalho pedagogico junto aos estudantes. Entendia-se que a polivalência promoveria uma transição mais harmônica para os graus mais elevados do ensino. Conforme Lima (2016), essas concepções nortearam a polivalência no Colégio de Aplicação, a partir dos anos 1960.

Entretanto, pela análise dos cadernos, foi possível perceber que a polivalência adquiriu diferentes nuances ao longo dos anos no Colégio de Aplicação. Entre 1978 a 1983, a professora trabalhava com os componentes curriculares de Língua Portuguesa, Matemática, Ciências e Estudos Sociais. A partir de 1984, houve mudanças, e ela começou a atuar como polivalente responsável apenas pelas áreas de Português e Estudos Sociais ${ }^{12}$. No caderno de 1985, nas últimas páginas, Isabel escreve reflexes acerca desse modo de ensino:

\begin{abstract}
"O por que da polivalência? A polivalência integral em quinta série e a semi-polivalência em sexta série tem o objetivo de atender as características peculiares de alunos desta faixa etária. A principal característica a ser considerada é a emocional... um pouco de referências, alguém que Ihe assegure estabilidade e segurança dentro do mundo escolar que para muitos é a continuidade das séries iniciais e, para outros, que ingressaram no Colégio de Aplicação nesta fase de escolaridade éuma experiência inéditarepleta deexpectativas, expectativas essas alimentadas pelas famílias" (caderno de 1984).
\end{abstract}

Na sequência, o texto explica que o conteúdo trabalhado em cada série seria desenvolvido "de forma não compartimentada, facilitando ao aluno constantes ocasiões para estabelecer relações, chegar a conclusões e emitir opiniões próprias formados à luz do que estudaram e elaboram" (1985). E, em relação à polivalência de Língua Portuguesa e Estudos Sociais, informa-se que a intenção seria integrar os conteúdos "naturalmente na forma em que vão surgindo e não artificialmente, propiciando um conhecimento mais amplo e facilitando ao aluno constantes ocasiões para estabelecer relações, chegar a conclusões e emitir opiniões próprias formados à luz do que estudaram e elaboram" (1985).

Em outro caderno (1982), encontrou-se uma folha solta com informações sobre a "avaliação dentro da polivalência (Estudos Sociais e Português)". Defende-se o propósito de uma avaliação integral, pois "só há condições de compreender e transferir bem o conteúdo de História e de Geografia se o aluno

objetivava a ampliação dos conhecimentos do aluno "iniciando-o em técnicas de artes aplicadas, adequadas ao sexo e à idade" (BRASIL, 1961, p.6). Para os alunos que cursavam as séries complementares, conforme a legislação era permitido o ingresso na $2^{a}$ série Ginasial, mediante aprovação em novo Exame de Admissão. Para maiores informações, consultar Lima, 2016.

${ }^{11}$ O CAp é uma escola que manteve o propósito de buscar novos métodos de aprendizagem, entre eles Classes Experimentais Secundárias, que objetivava a constituição de um campo de ensaio para aplicação de métodos pedagógicos, bem como de novos tipos de currículos. Por meio dessas Classes, idealizava-se uma escola que conciliasse o desenvolvimento intelectual e as habilidades práticas, por meio de currículo diversificado nos moldes observados especialmente na França. Portanto, infere-se que as Classes Experimentais brasileiras sejam apropriações das Classes Nouvellesfrancesas, considerando a circulação de educadores entre Brasil e França, naquele contexto (Lima e Almeida, 2018).

12 Essa informação foi localizada em uma lista de materiais colada no caderno de 1986, em que está escrito os nomes das professoras responsáveis pela "polivalência de Português- Estudos Sociais" e "Matemática-Ciências". 
realmente souber ouvir, ler e escrever decodificando a mensagem implícita e explicita, tanto de uma como de outra disciplina". Ainda, o texto esclarece que a avaliação deve considerar "o interesse do aluno, sua participação em grande e pequeno grupo, bem como seu envolvimento no trabalho individual pontualidade na entrega das tarefas (...)"

A análise dos cadernos permite inferir que a intenção do Colégio seria no sentido de promover uma educação imbuída dos ideais escolanovistas, ancorada nos princípios das classes experimentais francesas. Ao que tudo indica, havia naquele contexto escolar a preocupação em conhecer o aluno, em respeitar suas características etárias, por meio dos estudos de Psicologia, e, assim, mapear seu desenvolvimento. Essas concepções seriam a base para construir uma instituição educativa que tinha por objetivo maior oferecer um ensino qualificado para seus estudantes.

\section{ARQUIVOS PESSOAIS DE UMA PROFESSORA GUARDADOS NO ARQUIVO DA FACED/UFRGS}

Os cadernos, objeto de investigação deste artigo, hoje habitam o Arquivo de Memórias da Faculdade de Educação da UFRGS, afinal "a memória se enraíza no concreto, no espaço" (Nora, 1993). Neste lugar, conservam-se inúmeros documentos históricos, produzidos pela instituição ao longo dos anos, em suas mais diferentes instâncias. O Arquivo da FACED pode ser compreendido como uma espécie de refúgio, em meio às pressões do cotidiano de estudo e de trabalho. Como lugar, garante "vínculos entre passado, presente e futuro" (ANHEIN, 2018, p. 131), afinal mantém-se uma presença de testemunhos de tempos pretéritos que aspiram a presença também no futuro. Se interessa pelos "resíduos da escola que guardam segredos que afetam os silêncios da História da Educação" (ESCOLANO, 2017, p.38). Na esteira desse pensamento, cabe lembrar Nora, ao dizer que "os lugares de memória são antes de tudo restos" (1993,p.12), restos do que passou, "fragmentos de verdade, ofuscantes de nitidez e de credibilidade" (FARGE, 2009, p. 27).

Com relação aos cadernos, entendidos aqui como arquivos pessoais da professora Isabel, importa explicar o percurso que trilharam. Interessante saber que foram produzidos nas dependências do mesmo prédio em que hoje estão. Como dito anteriormente, o Colégio de Aplicação, durante muito tempo, ocupou alguns andares do edifício que hoje é utilizado exclusivamente pela Faculdade de Educação . Portanto, foi nas dependências do prédio da atual Faculdade de Educação/UFRGS que os cadernos foram escritos. Depois, estiveram por muitos anos guardados na casa da professora e, em 2012, retornaram para seu lugar de origem, o edifício chamado pelos antigos estudantes de torre azu/13. Hoje, encontram-se, junto com outros tantos documentos, na sala 610, em que funciona o Arquivo de Memórias da Faculdade.

No Arquivo da Faculdade, esses cadernos representam um conjunto documental importante. A professora, ao longo dos anos de trabalho, fabricou-os com artesania, pois observam-se dimensões autobiográficas na sua construção. Arquivar é um modo de testemunhar, de deixar registradas nossas memórias, nossas relações com os outros, enfim, nosso lugar no mundo. Portanto, embora carreguem uma

\footnotetext{
${ }^{13}$ A expressão "torre azul" era utilizada pelos estudantes do CAp ao referirem-se ao prédio da escola, em seus nove andares, destacando-se na arquitetura arrojada em meio ao Campus Central da UFRGS. Este tema foi abordado por Grimaldi e Almeida, 2018.
} 
marca institucional, também compõem um arquivo pessoal. Trazendo Sue McKemmish (2013) para a discussão, esses cadernos constituem-se em "provas de mim", mas também "provas de nós", ou seja, esses escritos de Isabel acerca de suas aulas no Colégio de Aplicação, representam indícios da cultura escolar daquela instituição especificamente e daquela temporalidade.

Notadamente em relação aos cadernos enquanto fontes para o campo da História da Educação, cabe dizer que houve um tempo em que não tinham a notoriedade que hoje possuem. Mas, diante do contexto da ampliação da noção documental, esse suporte de escrita passou a ser valorizado, em sua interface com "a preocupação dos historiadores em examinar o vivido na sala de aula" (MIGNOT, 2008, p. 7). Castillo Gomez (2012) observa o quanto vem se alargando o interesse por esses documentos, como uma dívida da História da Educação para com os materiais da ordem do comum, e, ao mesmo tempo, enfatiza a "inquietude por sua busca", afinal, sabemos que não são produzidos com vistas à perenidade. Tal situação reforça o entusiasmo dos pesquisadores ao se depararem com esses conjuntos documentais. É como o encontro de um tesouro que pode, enfim, ser explorado.

\section{EM CADA CADERNO: UM POUCO DA PROFESSORA, EM MEIO A PROTOCOLOS E À CULTURA ESCOLAR}

Os cadernos de planejamento em questão podem ser concebidos como janelas entreabertas, deixam ver um pouco de sua autora, das práticas de ensino, das metodologias trabalhadas, das concepções pedagógicas da escola, enfim, evidenciam aspectos das políticas públicas de educação de uma determinada época. Apresentam protocolos de escrita comuns a cadernos de professoras, portanto, em alguma medida, permitem que sejam definidos como escrituras disciplinadas (MEDA, 2014). Não seguem uma estrutura idêntica, embora a análise permita dizer que seguem modos semelhantes de descrição das aulas. Nenhum dos suportes de escrita analisados foi utilizado até o fim, em todos eles, encontram-se muitas folhas vazias.

Em relação à materialidade dos artefatos, destaca-se que são de grandes dimensões, em espiral, cada um contando com, em média, duzentas folhas, em que a docente expõe suas aulas. Nenhum foi encapado. Um aspecto a ser ressaltado é o fato da professora não ter o hábito de colar folhas nos cadernos e sim guardá-las dentro deles: textos mimeografados, trabalhos de alunos, rascunhos seus, folhas com listas dos nomes de alunos com avaliações dos mesmos, lâminas para projeção, envelopes, testes de alunos, reportagens de jornais.

As anotações nas últimas páginas dos cadernos são preciosas porque comumente escapam do regramento que caracteriza a escrita nas páginas anteriores. Assim, nesse espaço final, em 1985, indica pelo título "Caderno de caligrafia" os nomes dos alunos que, no seu entender, precisavam fazer uso dessa prática de escrita. Tal evidência faz pensar que o uso da caligrafia ainda era recorrente naquela temporalidade, mesmo para estudantes que já houvessem concluído os anos iniciais de alfabetização. Em 1986, divide as últimas folhas em quatro espaços/quadrados e coloca os nomes dos alunos, com observações acerca de alguns, de muitos nada diz e sobre outros registra: "é atento e participante, trabalha muito bem, suas contribuições positivas sempre acrescentam algo. Ótimo relacionamento com os colegas" ou "não traz os materiais quando se pede, esquece os livros da biblioteca. Desorganizado, não faz os 
trabalhos solicitados. Esquece tudo". Ainda no mesmo ano, nesse espaço final, descreve os "projetos individuais dos alunos", prática curricular da escola, Aqui reproduzo alguns dos títulos dos projetos: "Cinema gaúcho", "Crescimento do feijão", "Influência do vídeo game na vida das crianças", "Cobras", "Como cuidar do coração pelo alimento", "A história do dinheiro no Brasil", "Super heróis", "Aves".

Observa-se a presença de marcas pessoais nos modos da professora sistematizar as aulas. Ao folhear os cadernos, parece que os organizava a seu modo, sem muita preocupação com esmero. Entretanto, produz uma lógica própria, em que descreve a rotina diária, talvez como forma de melhor desenvolver seu trabalho. Essas observações levam a acreditar que esses materiais fossem manuseados exclusivamente por ela, não passavam pelo crivo de seus superiores, e essa constatação acentua uma dimensão autobiográfica, às vezes menos evidente em outros cadernos ${ }^{14}$.Neste sentido, em meio ao garimpo, observaram-se aspectos de ordem pessoal, em meio à narração de suas práticas. Em 25 junho de 1986, Isabel registrou "Faltei, doença do pai" e, nos dias subseqüentes, escreveu "Faltei Luto". Também os dias de greve, como eventos que mobilizaram docentes da escola pública nos anos 1980, foram destacados em letras maiúsculas em 1986. Escreveu em 15 de maio "GREVE", sendo que a paralisação estendeu-se até 03 de agosto, quando registrou "Retorno oficial do Colégio de Aplicação, atividades no grande grupo com explicações sobre o movimento e o por que do retorno. Manifestações dos alunos e sugestões para reformular o calendário escolar". O retorno oficial das aulas ocorreu de fato, Segundo suas anotações, dia 26 de agosto, quando reencontrou os estudantes. Para este dia, planejou o seguinte para recebê-los: "Conversar: sobre a greve (livre) sobre o que fizeram durante este período e o que leram. Como gostariam que o ano letivo transcorresse daqui para a frente?" Em seguida, indicou o trabalho a ser feito "após os alunos externarem oralmente os seus sentimentos, convidá-los a escrever em forma de redação o que sentiram com a greve, o que pensaram, o que fizeram, o que planejaram" (1986).

A autora também fez uso das contra capas para anotações diversas, como listas de livros que emprestava e para quem. Nesses apontamentos dos empréstimos, constam os títulos "Anarquistas graças a Deus", "Relatório do GEEMPA", "Admirável mundo novo" (1983) ${ }^{15}$. Por meio da observação minuciosa desses e de outros escritos de Isabel, podem-se conhecer alguns autores que faziam parte de seu repertório intelectual e que compareciam em suas aulas. Assim, no verso da capa do caderno de 1984 aparecem títulos de livros de História, "História da América", de Elza Nadai, "História Econômica do Brasil", de Caio Prado Junior, "Educação e Sociedade" (s/a) e "um artigo" de Marilena Chauí. Chama a atenção a aula do dia 11 de junho de 1985, quando planejou "ler para os alunos alguns trechos do livro Desenvolvimento Econômico e Evolução Urbana de Paul Singer", importante intelectual. Aqueles foram anos marcados pelo fim dos governos militares no país e o fato da professora acercar-se de pensadores como Marilena Chauí e preocupar-se em trazer Paul Singer para as suas aulas diz muito acerca de suas

\footnotetext{
14 Pesquisas sobre cadernos escolares de alunos e de professores foram objeto de estudo em Almeida, 2016 e Rosa e Almeida, 2018.

15 "Anarquistas graças a Deus" é um romance escrito por Zelia Gattai, publicado em 1979. Por meio de uma narrativa autobiográfica, a autora conta as memórias de sua família em São Paulo, no inicio do século XX. "Admirável mundo novo", de autoria de Aldois Huxley, narra uma distopia em que a trama se desenrola em Londres, no ano de 2540. O GEEMPA, Grupo de Estudos sobre o Ensino da Matemático em Porto Alegre, manteve intensas relações com a Faculdade de Educação/UFRGS, tendo entre suas fundadoras a professora Ester Grossi. Foi precursor nas discussões acerca de metodologias para o ensino da Matemática.
} 
posições políticas e sociais naquele momento em que o país apostava em um novo tempo de luta pela redemocratização.

\section{AULAS DE HISTÓRIA, EM TEMPOS DOS “ESTUDOS SOCIAIS”}

Após refletir, ainda que minimamente, acerca da relevância dos arquivos pessoais para as pesquisas inscritas no campo da historiografia da educação, de situar a instituição educativa em que os cadernos foram produzidos, e de se aproximar dos cadernos e de sua autora, aqui a intenção é analisar o que esses suportes de escrita, guardados por tantos anos, são capazes de fazer dizer acerca das aulas de História, inseridas nos "Estudos Sociais". Tal expressão representava as disciplinas de História e Geografia, da sexta série polivalente no Colégio de Aplicação entre os anos 1978 e 1986. A análise incidiu na perspectiva de um rastreamento de cada artefato individualmente, avaliaram-se suas especificidades e desenvolveu-se uma mirada no sentido de identificar práticas referentes às aulas de História, em suas regularidades e dissonâncias, ao longo dos anos.

Antes desse exame, cabe refletir acerca da historicidade do ensino de História no Brasil, sobretudo considerando os anos 1970 e 1980. Importa trazer para a discussão as implicações da Lei 5692/71, instituída pela Reforma da Educação Básica, para as disciplinas de História e Geografia. Pela legislação em questão, produto dos governos militares no país, criou-se o ensino por áreas de conhecimento, descaracterizou-se o ensino de História e Geografia no primeiro grau de ensino, portanto, negou-se o estatuto de disciplinas autônomas e ambas passaram a ser integradas sob a nomenclatura de "Estudos Sociais", (NADAI, 1993; FONSECA, 2003).

Como premissas básicas, cabe lembrar que durante os governos militares, os conteúdos de História, na disciplina Estudos Sociais, via de regra, apresentavam abordagens substancialmente políticas, generalizantes, com pouco espaço para as particularidades, em que se reproduziam práticas de períodos anteriores, pautadas na memorização de datas, no destaque a fatos escolhidos como relevantes, exaltando determinados personagens, condenando tantos outros ao esquecimento (MARTINS, 2014). A História, mais uma vez, durante os anos 1970 e 1980, estava a serviço do Estado para justificar um projeto de governo (FONSECA 2003).

Feitas essas considerações acerca dos estatutos legais do componente curricular "Estudos Sociais", chega-se ao momento de analisar como tais práticas comparecem nos cadernos. Reforça-se o fato da primeira diferença entre a polivalência exercida pela professora ao longo dos anos, pois, de 1978 a 1982, os cadernos apresentam a polivalência em sentido mais amplo, englobando conteúdos de diferentes componentes curiculares. A partir de 1984, constam nos cadernos apenas conteúdos de Língua Portuguesa e Estudos Sociais. É possível que, diante dessa mudança, tenha sido mais tranquilo para a professora desenvolver seu planejamento, de modo a contemplar maiores interlocuções entre esses saberes, tendo em vista sua formação em Ciências Sociais. Também é preciso levar em conta as relações de aproximação entre a Língua Portuguesa e os Estudos Sociais, no sentido da promoção da integração entre esses componentes curriculares. 
Em todos os cadernos, a professora apresenta os horários das disciplinas durante a semana. Às quartas feiras à tarde, em 1979, destaca que havia para ela "assessoramento em Estudos Sociais", situação comum no Colégio de Aplicação, recorrente em outros componentes curriculares. Podemos supor que tal assessoria fosse responsabilidade de professoras da Faculdade de Educação, haja vista as relações entre as duas unidades na UFRGS.

Entre 1978 e 1983, observa-se que foram previstas quatro horas aula para Estudos Sociais, sendo um período às segundas-feiras e os outros três juntos, às sextas-feiras. Nos cadernos desses anos, vê-se que se misturam eventos do calendário cívico e cristão com aulas de Estudos Sociais, por exemplo, usava-se o tempo desse componente curricular para ensaios e comemorações alusivos à Páscoa, Dia das Mães, Semana Farroupilha. Além disso, valia-se do tempo da aula de Estudos Sociais, geralmente às segundas-feiras, para discutir com a turma questões comportamentais/disciplinares, também para comemorar aniversários, desenvolver aulas sobre sexualidade, em separado para meninas e meninos. Como exemplo dessa prática, destaco o escrito em 9 de março de 1982, "fazer com os alunos um levantamento de alguns itens (normas) para que haja em sala de aula uma boa e produtiva convivência", completa na margem, "tomou todo o período". Em outra ocasião, ainda nesse horário de segunda-feira, em abril de 1983 diz, "conversa com os alunos sobre vários problemas que vêm aparecendo em aula como: muita conversa, pouco interesse, tipos de aula, formas de arrumar a sala para melhor produção".

Cumpre dizer que nos anos seguintes, até 1986, não mais se evidenciam essas práticas. O que se pode inferir? É possível que, nos anos 1970 até os primeiros anos da década seguinte, no CAp, ainda sobrevivessem concepções em que aulas de História confundiam-se com temas do calendário cívico e cristão e a professora aproveitasse esses períodos, talvez acreditando que seriam aqueles que mais se aproximavam de tais eventos celebrativos. É preciso dizer que essas práticas eram recorrentes no ensino de História, não sendo uma prerrogativa do Colégio de Aplicação. Mas, chama-se a atenção para o fato de, mesmo em uma instituição que se autodefinia a partir de uma determinada vanguarda pedagógica, ainda permanecerem em fins dos anos 1970, esses entendimentos em relação ao ensino de História e Geografia.

Entretanto, essas marcas pedagógicas positivas da instituição podem ser constatadas nos cadernos da sexta série polivalente. Ressalta-se, assim, as visitas de estudo previstas em cada ano letivo. Em todos os cadernos, há registros de duas grandes saídas de campo, para Rio Pardo, Caxias do Sul e Garibaldi, Tramandaí, Missões Jesuíticas, São Leopoldo. O propósito seria oportunizar experiências de aprendizagem de História e Geografia para além da sala de aula, Assim, os estudantes poderiam conhecer aspectos da colonização portuguesa na cidade de Rio Pardo, observar os traços da imigração alemã e italiana em São Leopoldo, Caxias do Sul e Garibaldi, estudar as características do litoral rio-grandense na viagem a Tramandaí e vivenciar as memórias deixadas por jesuítas e guaranis em um dos Sete Povos das Missões.

Percebe-se uma preocupação da professora em planejar cuidadosamente essas saídas e retomar o que foi visto no retorno às aulas. Em 1982, o foco de estudos era "a serra", em maio trabalhou "as origens da imigração alemã e italiana" por meio de pesquisas em grupo e, na sequência, fizeram viagem a Caxias do Sul, Farroupilha e Garibaldi. Antes da saída, escreve no caderno que "os alunos durante dois períodos tiveram livre acesso à biblioteca para consultarem sobre o trabalho de imigrações. A professora ficou em 
sala de aula dando assessoramento a quem pedisse, ajudando a procurar em livros, discutindo o assunto $e$ complementando informações". Tal registro indica uma disposição em promover momentos de alguma autonomia dos estudantes por trabalharem sozinhos, longe da docente. Outro exemplo é em 1985, quando iniciaram o estudo das Missões Jesuíticas, fazendo um levantamento sobre informações para depois assistir a um "áudio visual". Quando retornaram da viagem, discutiram "os aspectos atuais das Missões". A professora propôs a seguinte questão: "Se você fosse um índio das Missões Jesuíticas, como reagiria às investidas dos paulistas? Tente caracterizar o cenário da época".

Além disso, verifica-se que havia saídas mais curtas ao Planetário da UFRGS para estudos de Geografia e ao Salão de Atos da Universidade a fim de assistirem peças de teatro. Passeios na Feira do Livro da Cidade, atividades variadas no Parque da Redenção, visitas a exposições em diferentes museus, como a exposição de Leonardo da Vinci em 1986, idas ao cinema, parecem ter produzido um incremento cultural ao currículo escolar. É possível que a localização geográfica da escola, próxima ao Parque da Redenção e junto ao Centro Histórico da cidade facilitasse esses deslocamentos, considerando também que naquela temporalidade era outra a relação das pessoas com a região central da cidade, lugar em que havia efervescência cultural e comercial.

A partir de 1984, observa-se uma ênfase na intenção de valorizar aspectos subjetivos da aprendizagem, pois é solicitado que o estudante demonstre suas percepções acerca do que aprendeu e também se posicione diante dos fatos. Nesta perspectiva, ao trabalhar a Inconfidência Mineira, em 1984, a professora apresentou essas questões: "Será que Tiradentes foi um líder? Será que Tiradentes realmente corresponde à ideia de herói que atualmente é cultivada? Por que só Tiradentes foi enforcado e esquartejado?" Em 1985, a interdisciplinaridade passa a ser mais evidente nas intenções de aproximar o estudo de temas de História das aulas de Português. Em uma dessas propostas, trouxe para a aula um texto sobre "O Aleijadinho" e, ao mesmo tempo, poemas de Carlos Drummond de Andrade. Como continuação, trabalhos com expressão oral foram desenvolvidos: "procura caracterizar o espaço onde se desenrola a vida do Aleijadinho e a época em que ele viveu e criou sua obra". E chega o momento da proposição de discussões que envolviam conhecimento da História, análises sobre as desigualdades étnicoraciais e sociais do país, seguida de apreciações pessoais dos estudantes. Nas palavras de Isabel:

\footnotetext{
"procura responder: o pai do Aleijadinho era um carpinteiro português em Vila Rica. O que sabes sobre a vida das pessoas (trabalho, profissões, relacionamento, cultura, etc) que se fixavam na região de mineração no século XVII? A mãe de Aleijadinho era uma escrava alforriada. O que significa ser escrava alforriada? Sendo mulato, quais eram as chances do aleijadinho e de outros nas mesmas condições de se integrar na sociedade que se formava?" (LOSS, 1984).
}

Reflexões acerca de temáticas étnico-raciais comparecem nos cadernos de diferentes modos. Em 1984, os estudantes envolveram-se na "Gincana indígena". Chama a atenção a data escolhida para este evento: outubro e não abril, como talvez fosse o esperado naquela temporalidade. Desenvolver a gincana em outubro teria sido uma estratégia pensada pelas professoras para romper com a tendência de valorizar os indígenas apenas no dia 19 de abril?

Comumente, essas atividades desafiadoras mobilizam os estudantes a engajarem-se na temática proposta. É bem provável que a intencionalidade pedagógica fosse exatamente essa, de conduzi-los a pensarem nos indígenas no país de um modo diferente, questionando estereótipos ainda vigentes nos anos 
1980 em relação aos povos originários. Como atividade avaliativa ${ }^{16}$, apresentou-se um texto sem autoria, intitulado "O indígena é preguiçoso?", em que defende a posição contraria, algumas ideias do texto são, "criou-se essa imagem do indígena. E quem criou foram os brancos colonizadores...".

É preciso ter em vista que muitos dos discursos contemporâneos acerca das questões étnicoraciais não estavam postos naquele contexto. Talvez por isso o uso da palavra "tribo" 17 e a solicitação que os participantes caracterizassem um índio. O que estaria sendo esperado dessa caracterização? Algum estudante desenharia um indígena portando calça jeans, tênis e camiseta? Importa dizer que, nos anos 1980, a escola, em tese, ainda reforçava uma única representação desses povos, homogênea, como se só houvesse uma única cultura existente (BERGAMASCHI, 2012). Configurava-se uma visão atrelada ao passado, genérica, ao invés de promover um conhecimento das inúmeras etnias indígenas presentes em nosso país. Ao examinar esse trabalho desenvolvido, arrisca-se a dizer que o CAp avançava nessa discussão, demonstrava estar afinado com as grandes questões da educação do Brasil, antecipando, talvez, práticas que ainda hoje não são consenso na escola brasileira.

Neste sentido formativo, cumpre destacar leituras e autores que compunham a cena escolar nas aulas da sexta série em relação interdisciplinar com os temas estudados pela História. Assim, observam-se nos cadernos, de modo recorrente, poemas de Carlos Drummond de Andrade, Mario Quintana e Augusto Meyer, crônicas de Paulo Mendes Campos, histórias de Monteiro Lobato. Em relação a Mario Quintana, a professora, em1983, após apresentar o poema "Mapa da cidade", escreveu, "Quem viu o Fantástico18 de domingo onde declamaram Mario Quintana? O que sabem sobre o autor? O que gostariam de saber? O que acham que já leram da obra do autor?" E, depois, indicou a atividade a ser feita, "Escrever uma nova poesia, trazer uma música para inspiração, tu poderias transmitir o teu sentimento a respeito de nossa cidade como fez Quintana (ou bairro, ou rua, ou zona)?" Uma narrativa literária que apareceu em mais de um caderno é a obra "Os meninos da Rua da Praia", de Sergio Caparelli. Trata-se de um texto importante do ponto de vista formativo, de construção de cidadania por discutir a questão da exclusão social de crianças em Porto Alegre, tendo em vista que os protagonistas são meninos de rua que vivem no centro histórico da cidade.

Com relação aos textos trabalhados em aula, reforça-se a referência ao livro de Paul Singer lido para os alunos, conforme já mencionado. Os textos datilografados e mimeografados guardados em meio aos cadernos permitem que se identifiquem algumas fontes de consulta para planejamento de suas aulas. Para estudar a imigração alemã e italiana no RS, em 1982, valeu-se da Revista do Ensino ${ }^{19}$, que reproduziu

\footnotetext{
${ }^{16}$ A atividade avaliativa também traz questões gramaticais, especificamente sobre sujeito e predicado, usando frases sobre índios, em intenção interdisciplinar.

17 Segundo Baniwa (2006), o Movimento Indígena, a partir dos anos 1970, discute as novas formas de organização política, social e econômica dos indígenas. Entende a nomenclatura índios que designa os habitantes originários das terras do Continente Americano, mantendo a nomenclatura, sem esquecer que ela é produto de erro histórico pelos espanhóis no final do século XV. O índio, portanto, é aquele nativo de um lugar e cada um pertence a um povo, a uma etnia, identificado por autodenominação própria.

18 Programa de televisão da Rede Globo Fantástico, exibido aos domingos à noite, de ampla circulação naquela temporalidade.

19 A Revista do Ensino tornou-se um referencial para o magistério, especialmente para as professoras primárias do RS. Nela publicavam-se artigos sobre a educação no país, apresentavam-se modelos de planejamento de aulas de Ciências, História, etc, apresentavam-se sugestões de livros e músicas para serem trabalhadas com os alunos, entre outros. E, em muitos casos, aparecem
} 
textos de Helga Piccolo do livro "Imigração européia no RS" e de Valmiria Sanches20 "O italiano no Brasil”. No fim da página, destacou para cada um "texto adaptado a partir de ..., Revista do Ensino, Porto Alegre ano XXI n. 154-155 , 1974". Entretanto, logo em seguida, em 1986, outra fonte de consulta passa a se inserir nas práticas de leitura, a Revista Nova Escola21, com o texto datilografado e mimeografado "O açúcar". É possível que, à medida que os anos 1980 avançassem, a Revista do Ensino deixasse seu lugar de fonte de pesquisa privilegiada, considerando as novas literaturas pedagógicas que se inseriam no mercado editorial e se introduziam nas escolas, como é o caso da Revista Nova Escola.

Também cabe destacar, em 1985, a presença de textos de Sandra Jatahy Pesavento "Historia do RS: a expansão rumo ao sul: o Prata", referência para a historiografia rio-grandense. Sobre o tema da escravidão no Brasil, os estudantes tiveram contato com reflexões de Fernando Henrique Cardoso, com o texto "O papel do escravo negro no Rio Grande do Sul" e "Capitalismo e Escravidão no Brasil Meridional", adaptados pela professora. Ainda sobre este tema, localizou-se a indicação da leitura do capítulo "Doce Brasil”, do livro História da Sociedade Brasileira", de Francisco Alencar. Acerca desses textos, a professora costumava solicitar que os alunos produzissem esquemas ou resumos sobre os mesmos, provavelmente na intenção de promover sistematização dos conhecimentos adquiridos. Não se identificou em nenhum caderno modelos de questionários, atividades comuns nas aulas de História naqueles anos, via de regra pautadas na mera memorização de datas e fatos. Vale colocar o que ela diz em 1985 "trabalhar com os alunos como se faz um esquema relendo o texto usado e destacando a ideia principal e as idéias secundárias", evidenciando a preocupação em instrumentalizar os estudos para o entendimento da atividade a ser feita.

Nos anos 1980, verifica-se uma mudança no sentido de aproximar mais os conteúdos da História das vivências dos estudantes. Neste sentido, Isabel inicia os cadernos em todos os anos, a partir de 1982 , propondo a atividade de construção de "árvore genealógica", aproveitando para relacionar com fatos da Linha do Tempo do Rio Grande do Sul e de Porto Alegre, a partir da história do sobrenome dos alunos. Assim escreve a professora, "pedir aos alunos que organizem a linha de tempo de cada um ano por ano ou a cada dois anos a partir do nascimento e indicando em ordem cronológica os fatos mais importantes que marcaram a vida de cada um e tracem a história familiar, a procedência" (1982). Em 1985, previu sobre essa atividade, "chamar a atenção para os que não fizeram o trabalho completo". Colocou um lembrete para si mesma naquele mesmo ano "explicação do que é cronologia e divisão do tempo em séculos".

Em 1985 e 1986, nota-se que procurou organizar melhor a linha de estudos do sexto ano. Continuou iniciando o pela construção de uma linha de tempo de cada estudante articulada aos fatos maiores da história do Brasil. Na sequência, o estudo do "Descobrimento" da América, diferenças entre a colonização espanhola e portuguesa, a chegada dos jesuítas, incluindo o Rio Grande do Sul. Apresenta-se o papel do Estado como "abastecedor de alimento e transporte", por meio do estudo de mapas do caminho do gado até Sorocaba.

nos textos e imagens uma espécie de "modelo" da professora, que indicam padrões de comportamento, regramento moral, etc. Para maiores informações, ver Bastos, 1994.

20 Historiadoras, Helga Piccolo é professora da UFRGS, ambas escreviam textos historiográficos para a Revista do Ensino.

21 A Revista Nova Escola foi fundada em 1986 pela Editora Abril. Com edições mensais, era distribuída gratuitamente para escolas públicas do país. 
Outro aspecto em 1985 que chama a atenção é a abordagem sobre a história dos negros, para além da abordagem comum da escravidão. No dia 14 de maio, Isabel trabalhou uma reportagem de jornal intitulada "Movimento Negro nega a data de 13/05". Interessante que, em meio as folhas guardadas no caderno, estava a reportagem, na qual baseou sua aula. Assim registrou, "Leitura em voz alta pela professora, acompanhada de comentários do texto do jornal Zero Hora do dia 14/05 relacionando com o que foi estudado. Aula dialogada. Cada aluno redigiu uma apreciação sobre o que ouviu e discutiu e deverá trazer para amanhã". Pela proposição dessa atividade, pode-se observar o quanto estava atenta às informações que circulavam na grande imprensa, pois aproveitou uma notícia que foi publicada em 13 de maio para sua aula do dia seguinte, não perdendo assim a oportunidade de discutir uma tema sensível na história da sociedade brasileira.

Por fim, é preciso ressaltar a presença de um trabalho com os alunos acerca dos movimentos que conduziram à elaboração da Carta Magna do país em 1988. Desenvolveu em etapas o "Trabalho sobre a Constituição", em setembro de 1985. Em um primeiro momento individual, propôs que cada estudante elaborasse cinco perguntas sobre o assunto tratado em aula. Depois, solicitou que entrevistassem duas pessoas "professor, advogado, político, procurar em jornais e revistas artigos sobre o assunto, sublinhando o que achou importante e colando em folhas de desenho". Após, reuniram-se em grupos com a tarefa de construir "um jornal sobre a Constituição e a Constituinte, reunindo o que foi coletado através das entrevistas e recortes de jornais". Atividades como esta costumavam levar vários dias e isso pode ser constatado pela observação dos cadernos.

A mirada para a História nessas aulas de Estudos Sociais permite inferir que a professora valorizava esse componente curricular, procurando integrá-lo em perspectivas interdisciplinares. Atenta ao desenvolvimento dos conteúdos prescritos, não desviava o olhar do presente, procurando estabelecer relações com as questões que se colocavam no país naquele contexto. A realização de viagens de estudo, presença da literatura, atividades em grupo, desenvolvimento de pesquisas compunham o cenário das aulas dessa professora polivalente, no que se refere ao ensino de História.

\section{CONCLUSÕES}

Neste artigo, procurou-se analisar as dimensões que as aulas de História assumiam nas práticas de uma professora polivalente, pelo exame de seus cadernos de planejamento. Esses suportes de escrita considerados "lixos da escola" (ESCOLANO, 2017) são artefatos da ordem do comum que, quando investigados, promovem "visões inovadoras sobre o passado da educação" (ESCOLANO, 2017, P.34).

Por que mantemos conosco nossos cadernos? Cunha explica que "guarda-se para se guardar" (2008, p.112). Por meio dessa chave, podemos supor que a professora Isabel preservou esses arquivos, fabricados artesanalmente, pelos afetos que mantinha com seu trabalho, com sua escola.

Os anos 1970 e 1980 foram marcados pela fragilidade das disciplinas de História e Geografia nos currículos escolares que, pela legislação vigente, condensaram em "Estudos Sociais" no primeiro grau de ensino. O exame dos cadernos permite inferir que a professora procurava reconhecer as especificidades de cada disciplina, dedicando espaços igualitários para discussões dos temas pertinentes a cada componente curricular. As práticas observadas pelos registros nos cadernos apontam para intenções pedagógicas no 
sentido de aproximar os temas da História das vivências dos estudantes, pois eram estimulados a exercitarem a imaginação, a se colocarem no lugar do outro, praticando deslocamentos no tempo e no espaço. Além disso, vê-se o cuidado da professora em promover leituras de textos de diferentes intelectuais, bem como de fomentar a pesquisa como prática de sala de aula.

Encerra-se este texto com mais uma reflexão acerca da necessidade de, enquanto professores, estarmos atentos ao ensino de História que promovemos aos estudantes. Meditar sobre esse tema importa, tanto no presente como no passado. Remexer nos cadernos de Isabel Loss e localizar indícios de como preparava suas aulas permitiu descobrir que muitas práticas que hoje nos parecem inovadoras, já faziam parte da cena escolar há quarenta anos. Esses fragmentos de suas aulas, perenizadas nos cadernos, podem nos inspirar a exercitar micro-práticas de resistência, em tempos obscuros na história do Brasil.

\section{REFERÊNCIAS}

1. ALMEIDA, Dóris Bittencourt e LIMA, Valeska Alessandra de. O Colégio de Aplicação/UFRGS e a difusão das classes experimentais secundárias: entre o arquivo e a memória oral (1959-1981). Revista História da Educação. Porto Alegre, v.22, n.56, set/dez.2018, ISSN2236-3459. Disponível em https://seer.ufrgs.br/asphe. Acesso em 24/08/2019. doi. http://dx.doi.org/10.1590/2236-3459/77345.

2. ANHEIM, Etienne. Arquivos singulares - o estatuto dos arquivos na epistemologia histórica. Uma discussão sobre A memória, a história, o esquecimento de Paul Ricoeur. In. NEDEL, Letícia e HEYMANN, Luciana (orgs.). Pensar os Arquivos: uma antologia. Rio de Janeiro: FGV Editora, 2018.

3. BANIWA, Gersen. O índio brasileiro: o que você precisa saber sobre os povos indígenas no Brasil de hoje. Brasil, 2006 (wwwdominiopublico.gov.br).

4. BASTOS, Maria Helena. O novo e o nacional em revista: a Revista do Ensino do Rio Grande do Sul, 1994.357 p. Tese de Doutorado em Educação/USP, São Paulo.

5. BERGAMASCHI, Maria Aprecida. Povos indígenas: Conhecer para respeitar. In: BERGAMASCHI, Maria Aparecida (Org.).Povos Indígenas \& Educação. Porto Alegre: Mediação, 2012.

6. CUNHA, Maria Teresa Santos. O Arquivo pessoal do professor catarinense Elpídio o Barbosa (1909 1966): do traçado manual ao registro digital. Revista História da Educação, v.21, n.51, sete/dez.2017.ISSN2236-3459. Disponível em https://seer.ufrgs.br/asphe. Acesso em 24/08/2019. doi. http://dx.doi.org/10.1590/2236-3459/66723.

7. CUNHA, Maria Teresa Santos. No tom e no tema: escritas ordinárias na perspectiva da cultura escolar (segunda metade do século XX). In. BENCOSTTAa, Marcus Levy. Culturas escolares, saberes e práticas educativas (org.). São Paulo: Cortez, 2007. 
8. CUNHA, Maria Teresa Santos. Essa coisa do guardar... homens de letras e acervos pessoais. Revista História da Educação, v.12, n.25, sete/dez.2018. ISSN2236-3459. Disponível em https://seer.ufrgs.br/asphe. Acesso em 24/08/2019.

9. ESCOLANO BENITO, Agustin. A Escola como Cultura: experiência, memória e arqueologia. Editora Alinea: Campinas, 2017.

10. FARGE, Arlette. O Sabor do Arquivo. São Paulo: EDUSP, 2009.

11. FONSECA, Selva G. Caminhos da História ensinada. Campinas: Editora Papyrus, 2003.

12. GOMEZ, AntonioCastillo. Educação e cultura escrita: a propósito dos cadernos e escritos escolares.

Educação, Porto Alegre, v. 35, n. 1, , jan./abr. 2012. ISSN 1981-2582. Disponível em http://revistaseletronicas.pucrs.br/faced/ojs/index.php/faced. Acesso em 24/08/2019

13. GRIMALDI, Lucas Costa e ALMEIDA, Doris Bittencourt. A TORRE AZUL": memórias de espaços escolares pelas narrativas de estudantes e professores (1954-1996). Revista Educação em Questão. Natal. v.56, n.48, jul/set. 2018. ISSN 1981-1802. Disponível em: https://periodicos.ufrn.br/educacaoemquestao.doi. http://dx.doi.org/10.21680/19811802.2018v56n48ID15180. Acesso em 24/08/2019

14. LIMA, Valeska Alessandra de. Colégio de Aplicação da UFRGS: práticas educativas adormecidas entre o Arquivo e a Memória Oral (1954-1981). 2016,225 p. Dissertação de Mestrado - PPGEDU/UFRGS, Porto Alegre. LOSS, Isabel. Cadernos de planejamentos de aulas dos anos 1978, 1979, 1982, 1984, 1985, 1986. MCKEMMISH, Sue. Provas de mim... In. NEDEL, Letícia e HEYMANN, Luciana (orgs.). Pensar os Arquivos: uma antologia. Rio de Janeiro: FGV Editora, 2018.

17. MEDA, Juri. Escrituras escolares: contribuición a ladefinición de uma categoria historiográfica a partir de laprodución científica italiana em laultima década. In. IGNOT, SAMPAIO, PASSEGGI (orgs.) Infância, aprendizagem e exercício de escrita. Curitiba: CRV, 2014, p. 27-42.

18. MIGNOT, Ana ChrystinaVenancio (Org.). Cadernos à vista: escola, memória e cultura escrita. Rio de Janeiro: EdUERJ, 2008.

19. NADAI, Elza. O ensino da História no Brasil: trajetórias e perspectivas. Revista Brasileira de História. 
São Paulo. V.13, n.25-26, PP. 143-162, 1993.

20. NORA, Pierre. Entre memória e História: a problemática dos lugares. Projeto História. São Paulo, n.10, 1993. ISSN 2176-2767. Disponível em http://revistas.pucsp.br/revph. Acesso em 24/08/2019

21. SCHUTZ, Liane Saenger. Sotãos e porões: sacudindo a poeira do Colégio de Aplicação. 1994. $136 \mathrm{p}$ Dissertação de Mestrado - PUCRS, Porto AlegreANA, I. O ensino de história na ditadura civil militar com a institucionalização dos Estudos Sociais. Plural. Revista PPG Sociologia/ USP. São Paulo, v.21, PP.9-30, 2014.

VIÑAO FRAGO, Antonio. Historia de la educación y historia cultural. Posibilidades, problemas, cuestiones. Revista Brasileira de Educação. Campinas, v.42, n.32, .set/nov 1995.ISSN 1413-2478. Disponível em http://www.anped.org.br/siterbe. Acesso em 24/08/2019.

WERLE, Flavia. Colégio Sevigné e o Curso Complementar. In: TAMBARA, E.; CORSETTI, B.Instituições formadoras de professores no Rio Grande do Sul. vol. 2. Pelotas: Ed. UFPEL, 2008. p 159-192.

\section{Doris Bittencourt Almeida}

Doutora em Educação, Professora de História da Educação da Faculdade de Educação e do PPGEDU/UFRGS.

\section{Como citar este documento:}

ALMEIDA, Doris Bittencourt. Papeis que guardam memórias de uma professora polivalente: miradas para as aulas de história (colégio de aplicação/ufrgs - 1978- 1986). Reflexão e Ação, Santa Cruz do Sul, v. 27, n. 3, p. 57-71, oct. 2019. ISSN 1982-9949. Disponível em: <https://online.unisc.br/seer/index.php/reflex/article/view/13523>. Acesso em: doi:https://doi.org/10.17058/rea.v27i3.13523. 